\title{
The development of Time Series Sediment Trap control system Xufeng Sheng ${ }^{1}$, Haibin $\mathrm{Yu}^{{ }^{*}, 1,2, a}$, Xiaofei $\mathrm{Yu}^{3}$ \\ ${ }^{1}$ School of Electronic \& Information, Hangzhou Dianzi University, Hangzhou,310018, China \\ ${ }^{2}$ School of Information Engineering, Hangzhou Dianzi University, Hangzhou,310018, China \\ aemail:shoreyhb@hdu.edu.cn
}

Keywords: Sediment Trap;Automation;Low Power Consumption

\begin{abstract}
According to the application of sediments in the research of deep sea,this paper designed a kind of Time Series Sediment Trap control system.This system used MSP430 microprocessor, combined with the clock chip, stepper motor and sensors, realized the equipment working under water for a year,and recorded the running status information simultaneously. The test result shows that the system runs steadily, and meets the design requirement.
\end{abstract}

\section{Introduction}

Marine particulate matter records large quantity information of the biological activity,physical and chemical effect in the process of its formation, change and sedimentation[1].So since the first Sediment Trap developed late 1970s,it has been widely used in Particulate matter flux research,Marine sedimentology study,Global Change Study and Marine environmental monitoring research[2].

Early sediment trap can only obtain a single time particles,needs placed several times to collect samples with temporal resolution[3]. The Time Series Sediment can collect the marine particulate matter automatically according to the preset procedure timing[4].The collected samples have the correct time,exact numbers and high temporal resolution.The Trap firmware records operational conditions during the deployment including the sample collection date/time, an electronics self-diagnostic report before and after each sampling event, battery voltage and temperature information.So it has become an important means of Marine sedimentation particle collection[5].Due to the equipment needs to work underwater for a year,the low consumed power control and redundancy design is the research challenges.

\section{Design of the Sediment Trap control system}

The sediment trap structure shown in figure 1.PC connects to the control housing with RS232,setting the work cycle,placement,real time and position number.After the equipment into the water,it starts work automatically.Sample bottle keeps the particulate matter collected by the funnel.After a work cycle,the control housing controls the stepper motor to rotate,and then the rotator assembly will switch to another sample bottle. Position detection judges whether switch in position, if failed,it will inform the control housing to hand errors.After that,control housing saves the data collected by the temperature and angle sensor,then the system go into the sleep mode.After the equipment recycling,PC derives the stored information.

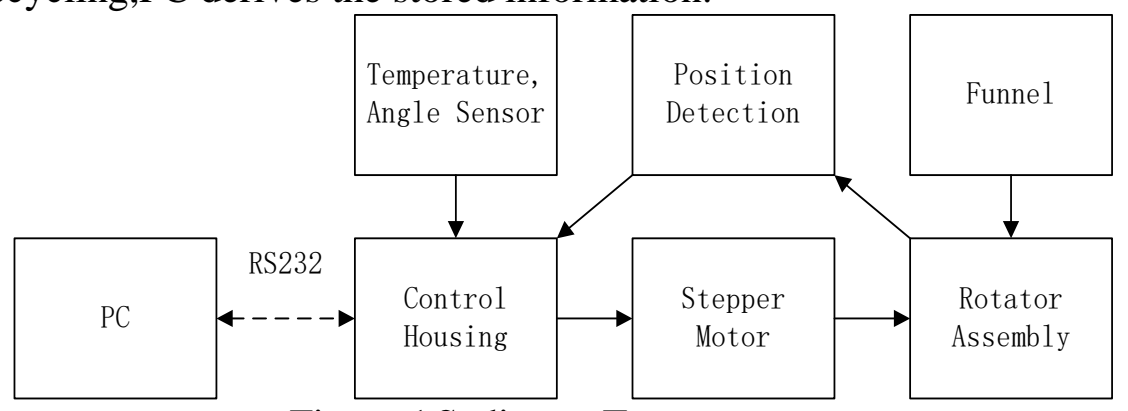

Figure 1 Sediment Trap structure 
The design requirements are as follows:

1. The sediment trap can sample for days to weeks,the longest work time is one year.

2. The sample bottles can switch automatically according to the preset time,and the working status information recorded completely.

\section{Hardware Design}

The system hardware design shown in figure 2.It includes main control module, sensor module, clock module, stepper motor driver module and power source.

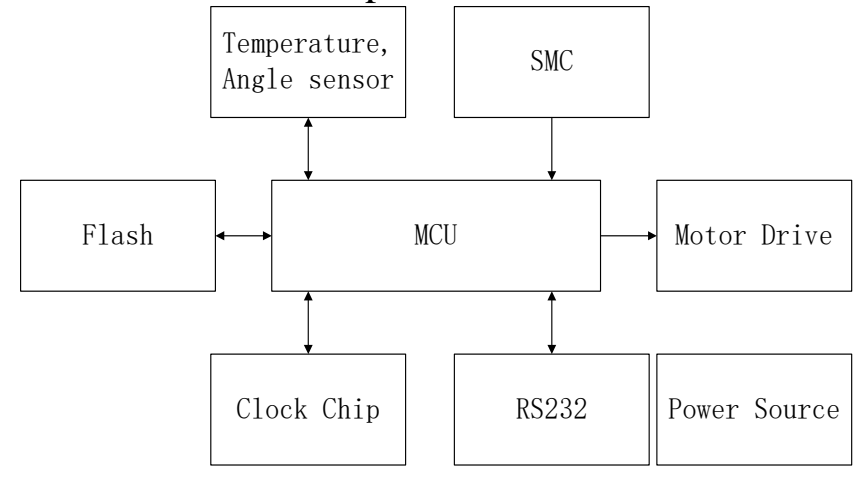

Figure 2 control system frame

For the low power cost,choose the American Texas instruments MSP430F149 as the processor[6].The architecture, combined with five low power modes is optimized to achieve extended battery life in portable measurement applications. The device features a powerful 16-bit RISC CPU, 16-bit registers, and constant generators that attribute to maximum code efficiency.The digitally controlled oscillator (DCO) allows wake-up from low-power modes to active mode in less than $6 \mu$ s.It configurations with two built-in 16-bit timers, a fast 12-bit A/D converter,two universal serial asynchronous communication interfaces,and $48 \mathrm{I} / \mathrm{O}$ pins.The abundant peripheral resources meet the requirement of the system design.

The sediment trap will incline under the influence of currents and waves,that can lead to overestimate or underestimate the actual settlement flux[7]. The angle sensor is used to provide a time history of tilt magnitude and direction to correct the settlement flux[8]:

$$
F=F_{T} \int_{0}^{\Delta T} \frac{1}{1+1.4 \sin 2 \theta} \mathrm{d}_{\mathrm{t}}
$$

In the type: $F$ is the settlement flux after correction, $F_{T}$ is the the actual settlement flux, $\theta$ is the angle of inclination, $\Delta T$ is the sampling interval.

Angle sensor adopts MPU6050 module,the module has built-in gesture solver, cooperate with dynamic kalman filter algorithm,can accurately output current stance under dynamic environment,it attains 0.01 degrees.

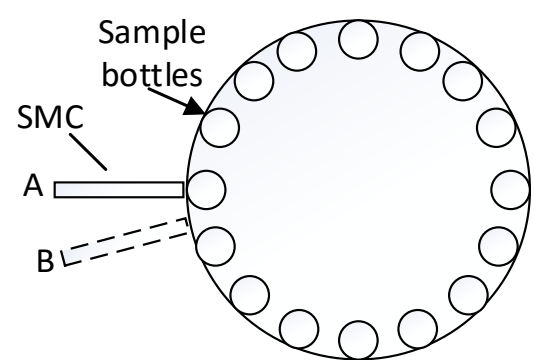

Figure 3 Position detection schemes

Position detection depends on the magnetic switch(SMC).As shown in figure 3,if the bottle reaches the right place as the status A,the distance between SMC and sample bottles is less than the trigger distance $(1.8 \mathrm{~cm})$, then the SMC will send a electrical signal to the MCU.If the bottle don't reach the designated position as the status B,the MCU would not received the electrical signal from the SMC.This is a disappointing situation, this means the sample bottle can not received the sediment collected by the funnel.So if the MCU still can't received the signal some time later,it will 
control the motor rotation until received the signal.

In this control system,a real-time chip is needed to provide an accurate calendar.Every sample bottle should be labeled in its own time.On the other hand,the power of the whole system provided by the battery in the control housing,if the MCU keeps working all the time,we need a more huge control housing to place more batteries,it is not conducive to maintenance or use the equipment.So we should control the MCU enter standby mode after the sample bottle switching. The real-time chip can used to wake up the MCU.The PCF8563 is a CMOS real-time clock/calendar optimized for low power consumption[9]. A programmable clock output, interrupt output and voltage-low detector are also provided. All address and data are transferred serially via a two-line bidirectional I2C-bus. Maximum bus speed is $400 \mathrm{kbits} / \mathrm{s}$.Experiments show that meets the basic system requirements.

Motor driver uses the slow step motor gear transmission way, the drive model is SD366[10].It is a three-phase hybrid stepping drive.The input voltage is $18 \mathrm{v} \sim 60 \mathrm{VDC}$, and the maximum driving phase current is 6.0 A.Using double pulse signal to control the step motor,it has stable and reliable performance and low calorific value.

\section{Software Design}

Software design includes the master control program, motor driver,data acquisition and storage,configuration software design four parts.Software flow chart shown in figure 4.

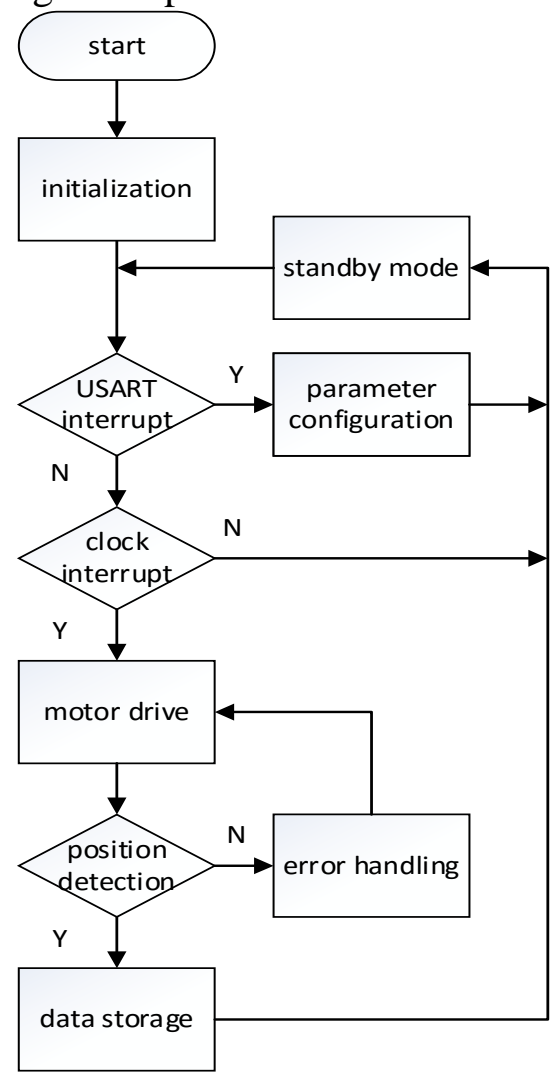

Figure 4 Software flow chart

Master control program consists of system initialization,parameter configuration and into low power mode.System initialization include of closing the watchdog timer,and initializing the system clock, I/O mouth, ADC, clock chip.

During the equipment working underwater,we unable to build a communication with the control housing,so we need configure the parameter before entering the water.When the MCU received the USART interrupt, it extracts the data packets form the PC,then writes the real-time clock and working cycle to the clock chip.Figure 5 is the PCF8563 register list,address from $02 \mathrm{H}$ to $08 \mathrm{H}$ records the time information,and from $09 \mathrm{H}$ to $0 \mathrm{CH}$ records the alarm information. When one or more of the alarm registers are loaded with a valid minute, hour, day or weekday and its 
corresponding AE (Alarm Enable) bit is a logic 0, then that information will be compared with the current minute, hour, day and weekday. When all enabled comparisons first match, the bit AF (Alarm Flag) is set.AF will remain set until cleared by software. Once AF has been cleared it will only be set again when the time increments to match the alarm condition once more. Alarm registers which have their AE bit set at logic 1 will be ignored.

\begin{tabular}{|c|c|c|c|c|c|c|c|c|c|}
\hline \multirow[t]{2}{*}{ Address } & \multirow[t]{2}{*}{ Register name } & \multicolumn{4}{|c|}{ BCD format tens nibble } & \multicolumn{4}{|c|}{ BCD format units nibble } \\
\hline & & $\begin{array}{c}\text { Bit } 7 \\
2^{3}\end{array}$ & $\begin{array}{c}\text { Bit } 6 \\
2^{2}\end{array}$ & $\begin{array}{c}\text { Bit } 5 \\
2^{1}\end{array}$ & $\begin{array}{c}\text { Bit } 4 \\
2^{0}\end{array}$ & $\begin{array}{c}\text { Bit } 3 \\
2^{3}\end{array}$ & $\begin{array}{c}\text { Bit } 2 \\
2^{2}\end{array}$ & $\begin{array}{c}\text { Bit } 1 \\
2^{1}\end{array}$ & $\begin{array}{c}\text { Bit } 0 \\
2^{0}\end{array}$ \\
\hline $02 \mathrm{H}$ & Seconds & VL & \multicolumn{7}{|c|}{ <seconds 00 to 59 coded in BCD> } \\
\hline $03 \mathrm{H}$ & Minutes & - & \multicolumn{7}{|c|}{$<$ minutes 00 to 59 coded in $\mathrm{BCD}>$} \\
\hline $04 \mathrm{H}$ & Hours & - & - & \multicolumn{6}{|c|}{ <hours 00 to 23 coded in BCD> } \\
\hline $05 \mathrm{H}$ & Days & - & - & \multicolumn{6}{|c|}{ <days 01 to 31 coded in BCD> } \\
\hline $06 \mathrm{H}$ & Weekdays & - & - & - & - & - & \multicolumn{3}{|c|}{$<$ weekdays 0 to $6>[1]$} \\
\hline $07 \mathrm{H}$ & Months/Century & C & - & - & \multicolumn{5}{|c|}{ <months 01 to 12 coded in $\mathrm{BCD}>$} \\
\hline $08 \mathrm{H}$ & Years & \multicolumn{8}{|c|}{ <years 00 to 99 coded in BCD> } \\
\hline $09 \mathrm{H}$ & Minute alarm & $\mathrm{AE}$ & \multicolumn{7}{|c|}{$<$ minute alarm 00 to 59 coded in $\mathrm{BCD}>$} \\
\hline $\mathrm{OAH}$ & Hour alarm & $\mathrm{AE}$ & - & \multicolumn{6}{|c|}{$<$ hour alarm 00 to 23 coded in $\mathrm{BCD}>$} \\
\hline $\mathrm{OBH}$ & Day alarm & $\mathrm{AE}$ & - & \multicolumn{6}{|c|}{$<$ day alarm 01 to 31 coded in $B C D>$} \\
\hline $\mathrm{OCH}$ & Weekday alarm & $\mathrm{AE}$ & - & - & - & - & $<w$ & y alarm & $>$ [1] \\
\hline
\end{tabular}

Figure 5 Register List

After working mode setting,the MCU enter the standby mode.MSP430 has 5 kinds of low power consumption(LPM0 LPM4).In LPM4,the MCU costs minimum,but it will close the ACLK clock which is used by USART.So we control the MCU go into the LPM3.

SD366 drive pulse sequence diagram shown in figure 6.T1 values is greater than 5us,shows the direction signal should be established before pulse signal.T2,T3 show the effective or invalid level width is greater than 2us. T4 said before enter into the lock state should to delay more than 20us.According to the sequence diagram,MSP430 sends a low level enable signal,then sends a direction signal after T4.In the end,it controls the motor rotate angle of 1.8 degrees for every 1200 pulse number.

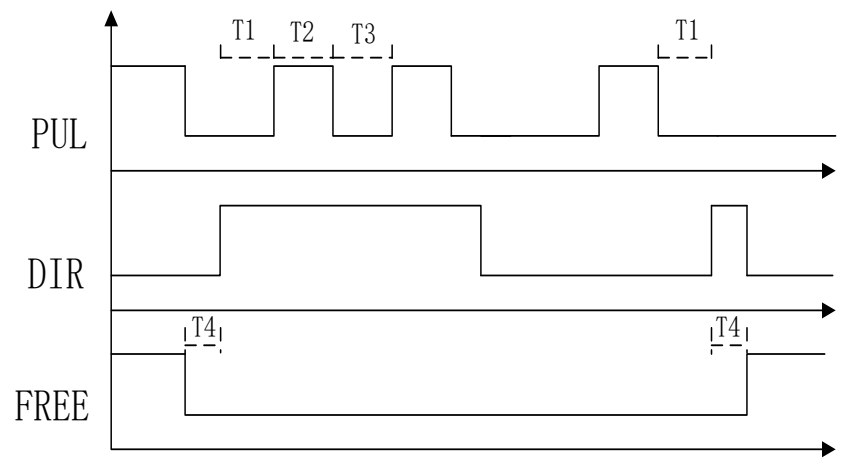

Figure 6 Pulse sequence diagram

The configuration software includes serial port setting,real-time clock setting,choosing work cycle,and data playback.The human-computer interaction interface is shown in figure 7.

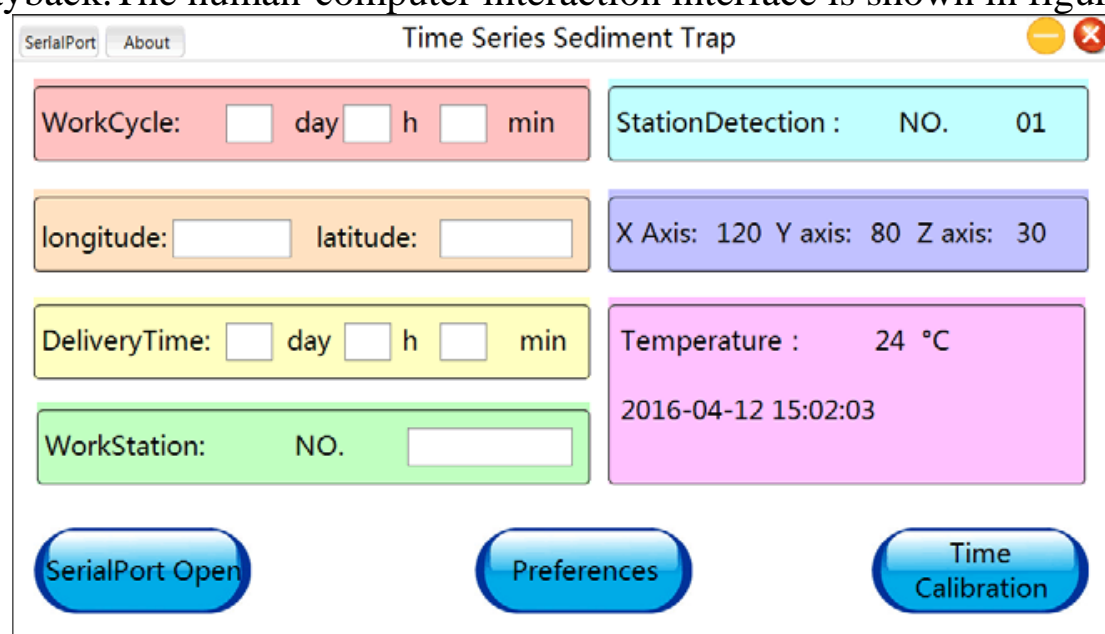

Figure 7 Human-computer interaction interface 


\section{Test results}

A week of testing under the laboratory environment, the power supply voltage is $27 \mathrm{~V}$,the equipment works stable and reliable,can switch sample bottle according to the predetermined time,and working status information record is complete. The system in sleep mode current is $0.87 \mathrm{~mA}$,motor rotates around current is $429.5 \mathrm{~mA}$.As this power dissipation,the equipment costs 7.62Ah one year,and the battery capacity is 10Ah,so this design meets the requirement of power dissipation.

\section{Conclusion}

In the process of sediment trap control system research,we through the system hardware and software of low power consumption and reliability design,meets the requirements of the control system design[11], and verified by experiments.In the future design of the sediment trap,we can increase the hardware and software interface of the water flow rate,temperature and salinity to improve the reliability of sediment samples[12].

\section{Acknowledgement}

This work was partially supported by National High-tech R\&D Program of China (863 Program) (Grant No. 2011AA090401) and China Ocean Mineral Resources R\&D Association Funding project(Grant No. DY125-11-T-01).

\section{References}

[1] Liu S F, Shi X F, Liu Y G, et al. Records of the East Asian winter monsoon from the mud area on the inner shelf of the East China Sea since the mid-Holocene[J]. Chinese Science Bulletin, 2010, 55(21):2306-2314.

[2] Wakeham S G, Lee C. Organic geochemistry of particulate matter in the ocean: The role of particles in oceanic sedimentary cycles[J]. Organic Geochemistry, 1989, 14(1):83-96.

[3] Honjo S. Material flux and models of sedimentation in the mesopelagic and bathypelagic zones[J]. Pharmaceutical Bulletin, 1962, 10:31-37.

[4] Honjo S, Doherty K W. Large aperture time-series sediment traps; design objectives, construction and application[J]. Deep Sea Research Part A Oceanographic Research Papers, 1988, 35(88):133 - 149.

[5] Wakeham S G. Sampling and experimental challenges for the next decade in marine organic chemistry — a prospectus[J]. Marine Chemistry, 1992, 39(s 1 - 3):239-242.

[6] Wei Y, Wang J, Li D, et al. Design of Intelligent Conductivity Meter Based on MSP430F149[C]// Computer and Computing Technologies in Agriculture III. 2009:240-247.

[7] Hajj T M E, Chieregati A C, Delboni Junior H, et al. Illusory reconciliation: the importance of sample representativeness[J]. Rem Revista Escola De Minas, 2013, 66(3):383-389.

[8] Bonnin J, Raaphorst W V, Brummer G J, et al. Intense mid-slope resuspension of particulate matter in the Faeroe - Shetland Channel: short-term deployment of near-bottom sediment traps[J]. Deep Sea Research Part I Oceanographic Research Papers, 2002, 49(8):1485-1505.

[9] Wang Y. Application of PCF8563 in electronic clock design[J]. Electronic Design Engineering, 2009.

[10] Sugiura K, Yasohara M. Motor driver: US, EP 1495534 A1[P]. 2005.

[11] Wang X, Zhang Y, Wang B. Research on reliability of turbine disk with random structure[J]. 
Engineering Sciences, 2010, 08(2):67-72.

[12] Kraver $\mathrm{K} \mathrm{L}$, Guthaus $\mathrm{M}$ R, Strong $\mathrm{T}$ D, et al. A mixed-signal sensor interface microinstrument[J]. Sensors \& Actuators A Physical, 2001, 91(3):266-277. 